\title{
RELASI PERAYAAN SABAT DENGAN KESUCIAN HIDUP MENURUT JOHN CALVIN
}

\author{
Rendy Tirtanadi \\ Gereja Kristen Rahmani Indonesia Kelapa Gading
}

\begin{abstract}
ABSTRAK: Ada suatu relasi antara perayaan Sabat dan kesucian hidup Kristen dalam pemikiran Calvin. Meskipun Calvin belum mengungkapkan relasi ini secara jelas, baik di dalam tafsiran, Institutes, katekismus, dan tulisan-tulisan Calvin lainnya, namun penulis mengamati bahwa relasi Sabat dan kesucian hidup menurut Calvin, secara tersirat telah dimulai sejak tafsiran kitab kejadian dalam Perjanjian Lama sampai tafsiran kitab Ibrani dalam Perjanjian Baru. Hal ini bukan hal yang mengherankan, karena tema kesucian memang sering dibicarakan Calvin dalam berbagai konteks pembahasan. Suatu kesucian yang bukan dari pemahaman yang self-centered, melainkan dari pengenalan dan penghormatan akan Allah, yang Godcentered. Penulis membagi ke dalam dua tinjauan untuk membuktikan relasi dalam pemikiran Calvin ini. Pertama, relasi perayaan Sabat dengan kesucian hidup Kristen secara personal dan kedua secara berjemaat/ gereja.
\end{abstract}

KATA KUNCI: Calvin, relasi, sabat, kesucian, asketik, kesalehan, istirahat rohani, persatuan mistis, natur dan atribut gereja.

ABSTRACT: There is a relation between the concept of the Sabbath and theholiness of the Christian life in the thought of Calvin. Even though Calvin has not revealed it clearly, either in his commentaries, Institutes, catechisms or other writings of Calvin, however the author observed that the relation between Sabbath and the holiness according to Calvin can be implicitly found in his commentaries from the book of Genesis in the Old Testament to the book of Hebrews in the New Testament. This is not surprising because 
the theme of holiness is often discussed by Calvin in various contexts of discussion. A holiness which is not from a self-centered understanding, but God-centered in recognition and respect of God. The author develops two reviews to prove the relation in Calvin's thought. First, the relationship between the observance of the Sabbath and the holiness personally and secondly according to congregational life/ church.

KEYWORDS: Calvin, relationships, sabbath, holiness, ascetic, piety, spiritual rest, mystical union, the nature and attributes of the church.

\section{Pendahuluan}

Teologi John Calvin yang seksama dan sekaligus praktis khususnya yang terkait dengan relasi perayaan Sabat dengan kesucian Kristen dapat dilihat dari: Pertama, pemahaman Calvin akan realitas kelemahankelemahan manusia sebagai konsekuensi hidup di dalam dunia yang sudah jatuh dalam dosa, dengan realitas akan tuntutan Allah yang maha suci, yang menghendaki Sabat yang suci bagiNya. Kedua, dalam khotbahnya tentang hari Sabat ${ }^{1}$ (Jumat, 21 Juni 1555), Calvin juga mengingatkan pendengarnya bahwa istirahat yang Allah telah sediakan dalam Sabat tidak lain adalah demi kebaikan manusia. Ketiga, menyadari akan bahaya sakralisasi terhadap hari tertentu, maka Calvin dengan sengaja tidak menyebutkan hari tertentu bagi perayaan Sabat, baginya substansi makna Sabat jauh lebih penting ketimbang "hari"nya.

\footnotetext{
1 Lih. John F.Thorton dan Susan B. Varenne ed,. John Calvin, Steward of God's Covenant (New York: Vintage Spiritual Classics, 2006), 333.
} 


\section{Pertimbangan Dua Macam Tinjauan}

Sistematika pembahasan artikel relasi perayaan Sabat $^{2}$ dengan kesucian hidup ${ }^{3}$ ini, dibagi ke dalam dua tinjauan. Pertama, tinjauan secara individual dan kedua, secara kolektif (jemaat/gereja). Pembagian ini, tidak dimaksudkan untuk membuat seolah-olah ada dikotomi antara kesucian secara individual dan kolektif, karena kedua tinjauan tersebut sesungguhnya terintegrasi. Tinjauan secara individual dan kolektif, adalah suatu cara penulis agar dapat membedakan lebih tajam pengaruh perayaandan pemahaman Sabat terhadap kesucian hidup Kristen.

\section{Relasi Perayaan Sabat dengan Kesucian Hidup Kristen secara Individual}

Relasi "One day in seven principle dengan Asceticism"

Konsep untuk memisahkan satu hari dari tujuh hari dalam seminggu merupakan konsep Sabat sejak penciptaan, sebelum manusia jatuh dalam dosa, dan berasal dari Allah Pencipta yang menciptakan manusia dan menaruh konsep waktu di dalam hidup manusia. Berbagai upaya dalam kebudayaan manusia telah berusaha mengubah konsep "one day in seven," dan tidak menghasilkan kebaikan bagi manusia. Di Perancis ada usaha memperpanjang siklus satu minggu menjadi sepuluh hari, ${ }^{4}$ di Soviet

2 Lih. artikel Rendy Tirtanadi, “Perayaan Sabat Menurut John Calvin” dalam Jurnal Teologi Verbum Christi, Vol. 2, No. 1, A pril 2015 (Jakarta: Sekolah Tinggi Teologi Reformed Injili Internasional), 184-216.

3 Artikel ini membatasi pandangan kesucian hidup menurut John Calvin hanya dari aspek asketisisme, kesucian, kesalehan, persatuan mistis, natur dan atribut gereja yang berkaitan dengan perayaan Sabat saja.

4 French republican calendar, diakses 1 September 2015,

http://www.britannica.com/science/French-republican-calendar. The calender dating system that was adopted in 1793 during the French Revolution and which was intended to replace the Gregorian calendar with a more scientific and rational system that would avoid Christian associations. The Revolutionary Convention established the calendar on October 5, 1793, setting its beginning to a date nearly a year prior (September 22, 1792), when the National Convention had proclaimed France a republic. The French republican calendar was based on a secular calendar calendar first presented by 
mencoba memperpendek siklus satu minggu menjadi lima hari. 5 Prinsip "one day in seven" dari perintah Allah ini, jika dikaitkan dengan perintah Sabat yang utama, bertujuan untuk menjaga kesucian hari yang dipisahkan itu.Hal ini senafas dengan arti kata "holy" yang berasal dari kata kerja "קָדוiט" yang berarti "to cut, separate" atau "dipotong, dipisahkan," dengan demikian kata "holy" ini tepat bila dipakai untuk menunjuk kepada sesuatu atau manusia yang telah dipisahkan dari kegunaannya yang umum dan ditempatkan secara khusus kepada Allah dan pelayananNya. ${ }^{6}$ Oleh karena itu hari Sabat sebagai hari yang dikhususkan bagi Allah menjadi "holy Sabbath" (Kel. 16:23). Allah yang suci, menuntut setiap orang yang datang padaNya juga suci seperti sifatNya itu (Imm. 19: 2; I Pet. 1:15-16).

Di dalam memahami prinsip "one day in seven" sebagai hari yang khusus dipisahkan dari enam hari yang lainnya itu, Calvin tidak dengan gamblang menyatakan bahwa hari ketujuh (hari Sabtu) atau hari pertama (hari Minggu), sebagai perayaan hari Sabat yang ditetapkan dalam kitab suci. Dengan kata lain, setiap orang Kristen boleh pergi beribadah pada hari lain, selain hari Minggu yang telah dipraktekkan oleh gereja mula-mula,

Pierre-Sylvain Maréchal in 1788. The 12 months of the calendar each contained three décades (instead of weeks) of 10 days each.

$5 \quad$ Five-day weeks, diakses 1 September 2015, https://en.wikipedia.org/wiki/Soviet calendar. From the autumn of 1929 until the summer of 1931, each Gregorian calendar year was usually divided into 72 fiveday weeks (=360 days), three of which were split into two partial weeks by five national holidays. The two parts of each split week still totaled five days - the one or two national holidays that split it were not part of that week. Each day of the five-day week was labeled by either one of five colors or a Roman numeral from I to $V$. Each worker was assigned a color or number to identify his or her day of rest. Eighty per cent of each factory's workforce was at work every day (except holidays) in an attempt to increase production while $20 \%$ were resting. But if a husband and wife, and their relatives and friends, were assigned different colors or numbers, they would not have a common rest day for their family and social life. Furthermore, machines broke down more frequently both because they were used by workers not familiar with them, and because no maintenance could be performed on machines that were never idle in factories with continuous schedules (24 hours/day every day). Five-day weeks (and later six-day weeks) "made it impossible to observe Sunday as a day of rest. This measure was deliberately introduced 'to facilitate the struggle to eliminate religion' The colors vary depending on the source consulted.

6 Herman Bavink, Reformed Dogmatics, Volume 2, ed. John Bolt, terj. John Vriend (Grand Rapids: Baker, 2003), 217. 
selama ia tidak mempercayai kesakralan atau ketakhayulan hari itu. ${ }^{7}$ Poin pentingnya adalah orang Kristen tidak boleh membuat dikotomi antara hari yang sakral dengan hari yang sekuler. Walau orang Kristen tidak mensakralkan hari tertentu, namun demikian tetap memerlukan satu hari tertentu demi holy occupation, suatu kegiatan yang suci pada hari itu. Sikap netralitas Calvin ini mungkin saja dipandang oleh kelompok tertentu sebagai suatu ambiguitas. Namun seperti pendapat banyak teolog yang menulis tentang teologi Calvin, di dalam memahami pemikiran Calvin maka tidak bijak jika menuduh kesalahan ajaran Calvin tanpa mempelajari keseluruhan dari ajarannya itu. ${ }^{8}$

Pemahaman yang salah terhadap perayaan Sabat dalam memaknai hari yang sakral dan sekuler, nyatanya juga telah mempengaruhi perilaku orang-orang di zaman Calvin hidup. Mereka yang ingin suci, menjadi seorang asketik, meninggalkan hal-hal tertentu dan menarik diri dari kehidupan dalam dunia yang dianggap sekular lalu masuk ke dalam komunitas yang rohani dan menjadikan dirinya sakral/ suci. Pandangan Calvin tentang asceticism ini dipertegas dengan penjelasan Abraham van de Beek, ${ }^{9}$ yang mengatakan keseluruhan hidup manusia telah ada dalam kuasa dosa, dan pilihan untuk meninggalkan sesuatu tidak secara otomatis membuat manusia menjadi suci. "Our best works are still defile by sin,... the evil that we would have to abstain from is not the quality of the world outside us, or of certain aspects of it, but is intrinsic in ourselves, We make the world evil." Dengan demikian penarikan diri dengan jalan membuang segala keinginan daging,

\footnotetext{
7 John Calvin, Institutes of the Christian Religion, ed. John T. McNeil (Philadelphia: Westminster, 1960), 2.8.34.

8 John Hesselink, Calvin First Catechism (Louisville: Westminster, 1997), 178. Sebagai pembanding penulis memberikan contoh dari Hesselink yang memberikan komentarnya tentang pemahaman seseorang akan doktrin Roh Kudus dari Calvin. Hesselink mengatakan "Ketika seseorang hendak memahami doktrin tentang Roh Kudus, maka orang itu harus mendiskusikan seluruh teologi Calvin yang membahas tentang Roh Kudus."

9 Lih. Abraham van de Beek, Reformed Theology Identity and Ecumenicity, ed. Wallace M. Alston Jr., Michael Welker (Grand Rapids: Eerdmans, 2007), 206.
} 
dan merenungkan perkara-perkara rohani, bahkan mengisolasi diri di suatu tempat suci, jauh dari segala pengaruh dunia adalah suatu tindakan yang sia-sia saja.

Memberikan waktu satu hari dalam tujuh hari kepada Sang Pemilik Waktu adalah sesuatu yang sangat wajar, sebagai ungkapan rasa hormat dan ucapan syukur seorang Kristen kepada Allah. Sebaliknya, mengabaikan perintah ini adalah suatu bentuk pemberontakan atas ketetapan Allah bagi manusia. Sesungguhnya semua hari adalah milikNya, karena Allah yang memiliki waktu. Namun jika Allah memerintahkan mengkhususkan satu hari untuk dijadikan sebagai hari Sabat, tidak lain adalah demi kebaikan manusia sendiri. Menjadi seorang Kristen yang memahami prinsip “one day in seven" seharusnya tidak meninggalkan dunia, karena dunia ini pun adalah milikNya, tetapi justru sebaliknya masuk ke dalam dunia untuk menggaraminya. Memberikan satu hari dalam seminggu saat merayakan Sabat adalah seperti yang Calvin katakan "being dead to our own inclination and works," sehingga menjadi seorang asketiksejati adalah suatu tindakan penyangkalan diri dan mematikan segala keinginan daging dengan cara membawa diri di bawah salib Kristus, tanpa harus meninggalkan dunia.

Bila seorang Kristen memahami makna rohani Sabat dari prinsip "one day in seven" ini, maka penulis berpendapat: Pertama, akan ada keseimbangan kerja dan istirahat di dalam diri orang Kristen itu. Karena memang Allah yang maha tahu yang telah meletakkan time table itu dalam diri manusia, maka hasilnya pasti menjadi baik adanya. Keseimbangan antara bekerja dan beristirahat, tentunya akan berpengaruh kepada kesehatan jasmani dan rohani orang Kristen itu. Kedua, prinsip "one day in seven" ini akan membuat orang Kristen terhindar dari pandangan dualisme, antara jenis pekerjaan yang sakral dan sekuler, karena setiap pekerjaan yang dikerjakan sesuai dengan panggilannya adalah sama baiknya di hadapan Allah. Dengan demikian persoalannya bukan tentang apa yang "saya pegang," namun lebih kepada "ke mana arah hati saya." Jadi seorang 
Kristen yang berada di gereja, belum tentu menunjukkan ia sedang beribadah. Sebaliknya, bisa saja seorang Kristen yang sedang bekerja adalah orang Kristen yang sedang beribadah kepada Tuhan.Hal ini sejalan dengan pandangan Calvin bahwa "bekerja" merupakan suatu panggilan Allah. ${ }^{10}$

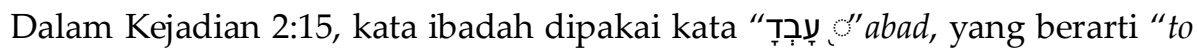
work, to serve," dan di dalam terjemahan New American Standard digunakan kata "to cultivate."11 Di sini terdapat relasi antara to serve, worship, dengan "to cultivate" yang merupakan asal kata "culture." Sebelum manusia jatuh dalam dosa Alkitab tidak mengenal dualisme, tidak ada ketegangan antara "to serve" dengan "to cultivate." Namun setelah manusia jatuh dalam dosa, ada kemungkinan Kristus menentang kebudayaan yang bertentangan dengan kebenaran. Di dalam Alkitab, urusan mengolah "garden" pun termasuk dalam ibadah, jadi bukan hanya urusan penginjilan, atau pergi ke gereja saja yang dianggap sebagai ibadah. Menyembah Tuhan, dalam mengelola tanah, tetap sama nilainya dengan menyembah Tuhan di dalam gereja. Dengan demikian seorang Kristen akan bekerja dengan tanggung jawab dan kualitas yang tinggi, demi kemuliaan Allah dan di hadapan Allah. "Coram Deo"12 bukan hanya menjadi slogan, tetapi merupakan sebuah kesadaran bahwa seseorang sedang hidup dalam hadirat Allah, di hadapan Allah yang maha tahu dan maha hadir. Konsekuensinya, apapun yang dilakukan baik enam hari kerja maupun satu hari ibadah memiliki nilai yang sama bagi seorang Kristen. Ketiga, seorang Kristen akan memiliki kesadaran bahwa dunia ini memang telah tercemar oleh dosa, kesempatan satu hari Sabat yang Allah

10 Calvin, Institutes 3.10.6. "...he has appointed duties for every man in his particular way of life. And that no one may thoughtlessly transgress his limits, he has named these various kinds of living "callings." Therefore each individual has his own kind of living assigned to him by the Lord as a sort of sentry Post, so that he may not heedlessly wander about throughout life."

11 Kej. 2:15 "Then the LORD God took the man and put him into the garden of Eden to cultivate it and keep it." (New American Standard Bible).

12 "Coram Deo is a Latin phrase translated "in the presence of God" from Christian theology which summarizes the idea of Christians living in the presence of, under the authority of, and to the honor and glory of God."diakses 2 Maret 2016, https://en.wikipedia.org/wiki/Coram_Deo. 
tetapkan dalam prinsip "one day in seven" justru menjadi hari yang penuh anugerah, sukacita dan damai sejahtera Allah, karena mengizinkan Allah bekerja saat orang percaya itu beristirahat. Jadi harus ada "rest to" dan juga "rest in" the Lord. ${ }^{13}$ Keempat, prinsip "one day in seven" ini, akan semakin meningkatkan ucapan syukur kepada Allah, karena menyadari bahwa Allah sebenarnya berhak atas tujuh hari yang Ia miliki, namun karena Allah memahami kelemahan manusia, maka Ia dalam kemurahanNya yang besar itu telah memberikan enam hari bekerja dan hanya meminta satu hari Sabat sebagai milikNya. Semakin seorang Kristen merenungkan kemurahan Allah, semakin ia akan menghargai kesempatan/ waktu satu hari yang Allah berikan, agar dapat beribadah ke gereja setiap hari Minggu dengan rasa syukur yang mendalam kepadaNya.

\section{Relasi Spiritual Rest dengan Kesucian}

Walaupun dalam "spiritual rest," Allah tetap bekerja menyucikan umatNya, maka sebagai umat Allah tidak boleh bermalas-malasan, tertidur, tidak melakukan kegiatan apapun. ${ }^{14}$ Pemahaman rest di sini harus dimaknai dua arah, yaitu rest in yang berarti berhenti dari bekerja dan rest to yang berarti beribadah kepada Allah, seperti yang diungkapkan John Murray. ${ }^{15}$ Berulang kali Calvin mengatakan bahwa melalui Sabat, maka Allah dikenal sebagai penyuci umatNya. ${ }^{16}$ Dengan demikian ketika prinsip ini dilaksanakan, umat Allah dapat menjalani hidup yang suci. Kesucian orang percaya ini merupakan konsekuensi dari: Pertama, adanya relasi dengan Allah yang suci, seperti ranting anggur yang senantiasa harus terhubung dengan Pokok Anggur itu. Dengan demikian relasi ini menunjukkan bahwa

13 John Murray, Collected Writings of John Murray (Edinburgh: The Banner, 1976), 210.

Dijelaskan perihal "rest to" dan "rest in" berarti merayakan Sabat bukan hanya beristirahat dari kegiatan, namun juga beristirahat dengan jalan beribadah secara khusus kepada Tuhan.

14 Bdk. G.I Williamson, Pengakuan Iman Westminster (Surabaya: Momentum, 2012), 264.

15 Murray, Collected Writings, 210.

16 Calvin, Institutes, 2.8.28. 
aspek kesucian sangat bergantung kepada Allah Tritunggal dan setiap orang percaya menerimanya secara pasif; disucikan oleh Kristus melalui pekerjaan Roh Kudus. ${ }^{17}$ Namun berhubung orang Kristen masih tinggal dalam dunia yang tercemar dosa, maka orang Kristen pun diperlengkapi Allah untuk menyucikan diri secara aktif dengan cara mengabdikan seluruh waktu dan dirinya kepada Allah. ${ }^{18}$ Dengan demikian setiap orang Kristen juga memiliki peran dan tanggung jawab untuk terus menerus mempertahankan dan memperjuangkan relasinya dengan Allah Tritunggal, agar kesucian hidupnya semakin nyata. Kedua, adanya ketaatan untuk melaksanakan perintah Sabat sebagai bukti adanya iman. Suatu iman yang aktif, yang memimpin setiap orang percaya untuk taat melakukan apa yang Tuhan perintahkan. Iman di dalam dan yang berasal dari Kristus ini pula yang akan diterima oleh setiap orang percaya, sehingga memperoleh pembenaran dan penyucian dari segala dosa dan kejahatannya. Seperti Yakobus katakan bahwa iman harus disertai perbuatan, demikian pula Anthony A. Hoekema ${ }^{19}$ mengingatkan bahwa penyucian sebagai karya anugerah dari Roh Kudus, yang mengikutsertakan tanggung jawab orang percaya untuk berpartisipasi didalamnya, sehingga Roh Kudus yang telah menyucikan orang Kristen, kini memampukannya untuk menjalani hidup dalam kesucian ketika merayakan Sabat. Berkomunikasi dengan Allah melalui doa dan pencerahan akan kebenaran kitab suci. Dengan demikian perayaan Sabat dapat menjadi "spiritual rest" yang sesuai dengan kehendak Allah. ${ }^{20}$

Sesuai dengan arti kata "holiness" dimana untuk menjadi suci, maka harus "dipisahkan," demikian pula halnya dengan Sabat, orang Kristen bukan hanya harus memisahkan satu hari untuk rest dari dosa tetapi juga

\footnotetext{
17 Yoh. 17:19; 1Kor. 6:11

18 Rom. 12:1; 2Kor. 7:1; 1Tes. 4:3; Ibr. 12:14

19 Stanley Gundry N., ed., Five views on Santification (Grand Rapids: Zondervan, 1987), 61.

20 Bdk.Richard B. Gaffin, Calvin and the Sabbath (Fearn: Mentor, 1998), 79. Gaffin mengatakan "the core of fourth commandment is the obvious answer...practicing a perpetual rest from sin, meditating privately"
} 
rest untuk mendapatkan kesucian dari Allah sendiri. Di tengah-tengah dunia yang tidak memerlukan istirahat, Allah justru menyediakan bukan hanya istirahat dari dosa, tetapi juga istirahat di dalam kesucian Allah. James Montgomery Boice mempertanyakan mengapa ketika berbicara tentang rest di dunia yang restless ini orang tidak mau mempercayai Injil? Jawabannya adalah karena rest berhubungan dengan kesucian dan dunia tidak menginginkan kesucian. ${ }^{21}$

Calvin mengkritisi kesucian orang yang merayakan Sabat dengan beberapa faktor sebagai berikut:

Pertama, apakah Sabat yang dijalankannya hanya sebatas sebagai "religious duties" seperti orang-orang Yahudi yang menjalankan Sabat dalam zaman nabi Amos, atau seperti orang-orang Farisi di zaman Yesus dalam Perjanjian Baru? Pada zaman nabi Amos, umat Allah menjalankan Sabat bukan untuk mencapai "spiritual rest" yang membawa keuntungan rohani yaitu mendapatkan kesucian dari Allah, namun sebaliknya justru merayakan Sabat adalah suatu kerugian karena tidak dapat keuntungan sebagai dampak dari larangan berdagang di hari Sabat. Demikian pula dengan Sabat orang Farisi yang mempraktekkan tradisi yang diberlakukan pada hari Sabat, "spiritual rest" justru menjadi beban dan suatu kemunafikan bukan kesucian. Dari dua contoh di atas, terlihat bahwa jika Sabat dijalankan hanya sebatas "external observance" atau "external form religion" saja, maka "spiritual rest" sejati yang membawa seseorang kepada kesucian hidup tidak akan pernah tercapai. Penyebabnya adalah kesucian yang diperoleh dari perayaan Sabat bukan kesucian yang berpusatkan pada dirisendiri, melainkan berpusatkan pada Allah.

Kedua, Sabat juga merupakan pertumbuhan kesucian jangka panjang, artinya ada suatu proses penyucian yang harus terus berlangsung di

\footnotetext{
21 James Montgomery Boice, An Expositional Commntary, Genesis Volume I Creation and Fall, Genesis1-11 (Grand Rapids: Baker, 1998), 103.
} 
sepanjang kehidupan Kristen.22 Tidak ada jalan singkat menuju kesucian, namun Roh Kudus memberikan prinsip-prinsip seturut dengan firmanNya melalui berpikir, berlatih dan bergumul di dalam pimpinanNya. Bisa saja Allah mengizinkan berbagai ujian terjadi pada enam hari kerja, sehingga manusia terus memandang kebawah ke dalam dunia ini, dan pada hari Sabat itu, manusia kembali berpaling memandang ke atas kepada Allah di surga untuk kembali disucikan olehNya. ${ }^{23}$

Ketiga, "spiritual rest" dalam Sabat bukan hanya berarti beristirahat dari kegiatan fisik tetapi justru berarti suatu tindakan aktif untuk datang meresponi undangan Yesus dalam Matius 11:28, yaitu dengan meninggalkan kemewahan dunia dan menyingkirkan keyakinan yang keliru, lalu sebagai orang yang tidak berdaya datang kepada Kristus. Calvin mengatakan bahwa peristirahatan di dalam Kristus merupakan kelepasan akan pengampunan dosa yang memberikan kedamaian: "The relief which he promises consists in the free pardon of sins, which alone gives us peace." 24 Kedamaian ini pula yang menjadi salah satu unsur penting bagi Stephen Tong ketika mendefinisikan Sabat yang memberikan spiritual rest, "Bagi saya, istirahat adalah tidak punya rasa cemas, khawatir, tegang (stress), menikmati damai, dan penyertaan Tuhan yang indah. Itulah Sabat." 25 Suatu kedamaian yang dianugerahkan ketika seorang Kristen menikmati "spiritual rest"dalam hadirat Allah yang maha suci yang dinyatakan di dalam Kristus.

Keempat, relasi antara "spiritual rest" Sabat dengan kesucian bergantung dari bagaimana cara merayakan Sabat itu sendiri. Seperti yang dikatakan Calvin "God as the sanctifier." 26 Orang Kristen harus berhati-hati

22 Calvin, Institutes, 3.3.6.

23 Thomas Watson, The Ten Commandments (Pennsylvania: The Banner of Truth Trust, 1959), 94. "Salah satu alasan Allah memberikan Sabat adalah demi kepentingan orang percaya dan berguna untuk meningkatkan kesucian."

24 Calvin, Commentary on a Harmony of Evangelists, 44.

25 Stephen Tong, Sepuluh Hukum-Hukum Keempat, diakses 28 Oktober 2014, http://www.buletinpillar.org/transkrip/sepuluh-hukum-hukum-keempat.

26 Calvin, Institutes, 2.8.28. 
karena Sabat bisa terjebak dalam formalitas belaka, seperti dahan kering yang siap gugur dan kondisi seperti ini banyak terjadi pada orang Kristen masa kini. Bruce A. Ray dalam "Celebrating the Sabbath"27 mengumpamakan dahan kering itu sebagai seorang Kristen yang memiliki bentuk kesalehan tetapi menyangkali kuasanya (2 Tim. 3:5) dan nabi Yesaya membawa pokok masalah dari kontroversi perayaan Sabat yang sebatas formalitas kepada fokus yg lebih jelas dan tajam dengan mempertanyakan: Hari siapakah itu? Bagaimana kehendak Tuhan untuk saya agar dapat menggunakan hari itu demi kebaikan dan kemuliaanNya? (Yes. 58:13-14).

Dengan memperhatikan uraian di atas, maka penulis menyimpulkan bahwa relasi "spiritual rest" dengan kesucian Kristen terintegrasi ketika seorang Kristenmau datang kepada Allah dalam SabatNya dan merelakan Allah bekerja di dalam dirinya, seperti yang dikatakan Calvin bahwa manusia bagaikan domba yang tercerai berai dan tersesat masuk dalam dunia "labyrinth," namun bersyukur kepada Allah, Ia telah mengumpulkan dan menyatukan kita denganNya dengan kesucian. ${ }^{28}$

\section{Relasi Sabat Anak Manusia dengan Kesalehan}

Sabat yang sebatas penerapan yang harfiah akan berakhir pada Sabat yang penuh dengan kesalehan yang palsu. Hal ini sudah terjadi ketika Yesus berhadapan dengan orang Farisi $^{29}$ yang merasa dirinya benar-benar memelihara hari Sabat. Kepalsuan orang Farisi itu ditunjukkan dengan perayaan Sabat yang berdasarkan pada tradisi para tua-tua Yahudi yang terefleksi dalam Talmud, dan bukan menurut Sang Pemilik Sabat yaitu

\footnotetext{
27 Bruce A. Ray, Celebrating the Sabbath (Phillipsburg: P\&R, 2000), 91.

28 John Calvin, The piety of John Calvin, A Collection of His Spiritual Prose, Poems, and Hymns, terj. Ford Lewis Battles (Phillipsburg: P\&R, 2009), 72.

29 Mat. 12:1-8; Kisah perdebatan Sabat di Ladang Gandum; Mrk. 3:1-6, Perdebatan Sabat saat penyembuhan; Luk. 13:10-17, Konflik Sabat tentang perempuan yang cacat; Luk. 14:1-6, Sabat penyembuhan penyakit busung air; Yoh. 5:1-9, Perdebatan Sabat di kolam Betesda; Yoh. 9:1-41, Sabat dan penyembuhan dengan air ludah.
} 
Kristus sendiri. Kesalehan yang palsu dari para orang Farisi itu tercermin dalam kesalahan ketika menafsir Sabat berdasarkan perbuatan, bagi orang Farisi Sabat harus dijalankan tanpa/ sedikit pekerjaan saja, orang Farisi tidak mampu membedakan perbuatan yang "diperbolehkan" pada hari Sabat ("necessity, mercy and piety works").30 Di sini Yesus justru membenturkan pemahaman yang salah dari orang Farisi tersebut dengan menunjukkan bahwa di hari Sabat Ia justru bekerja seperti Bapa di Sorga yang bekerja. Yesus mengoreksi Sabat orang Farisi yang penuh kemunafikan dengan Sabat Allah yang sejati.

Tidak bisa dipungkiri bahwa ada perbedaan antara tubuh dan jiwa, tetapi Alkitab memberikan pemahaman yang integratif. Pandangan Neoplatonis yang mengatakan bahwa tubuh adalah penjara jiwa, makanan jiwa, tidak ada pelayanan bagi tubuh, yang ada hanyalah pelayanan bagi jiwa, tidak sesuai ajaran Alkitab. Pelayanan Yesus menyangkut kedua aspek tersebut, baik tubuh maupun jiwa. Perayaan Sabat Anak Manusia bukan hanya menyangkut perihal jiwa tetapi juga tubuh yang terintegrasi. Yesus membukakan kebenaran Sabat, yaitu antara Sabat dengan kesalehan yang palsu dan Sabat dengan kesalehan yang sejati.

Orang Farisi yang merasa diri benar, walaupun mata jasmaninya melihat, ternyata mata rohaninya buta. Mereka memakai hukum yang dibuatnya sendiri untuk menentukan pelanggaran Sabat. Suatu kesalehan yang diciptakan sendiri, yang tidak mungkin diperoleh tanpa mereka datang kepada sang pembuat Sabat itu sendiri. Seorang teolog Reformed Belanda, Jochem Douma, dengan tegas mengatakan Sabat model orang Farisi sebagai Sabat kemunafikan. ${ }^{31}$ Suatu kesalehan yang kontras dengan pietas yang ditunjukkan Alkitab. Kesalehan yang benar adalah menghormati kebesaran Allah dan sekaligus memiliki kedekatan dengan

\footnotetext{
30 Murray, Collected Writings, 67.

31 Jochem Douma, The Ten Commandments, Manual to the Christian life (Phillipsburg: P\&R, 1996), 117.
} 
Allah dalam kasih akan Dia. Dalam kesalehan yang sehat terdapat keseimbangan antara mengagungkan kebesaran Allah dengan mengasihi Allah, Allah yang transenden sekaligus juga adalah Allah yang imanen. Dalam hal ini konsep pengenalan Allah harus beres terlebih dahulu sebelum memelihara Sabat yang sejati, dan konsep pengenalan diri harus beres dahulu sebelum dapat menerapkan kesalehan yang benar. Seperti yang dikatakan Calvin "Without knowledge of God there is no knowledge of self." 32 Bila konsep pengenalan Allah sudah beres, maka pemeliharaan Sabat seperti yang dinyatakan oleh Yesus sebagai Anak Manusia, bukan hanya akan menghormati dan mengasihi Allah sebagai pemilik Sabat, namun akan memengaruhikesalehan manusia dengan melakukan perbuatan-perbuatan yang berbuah kebaikan di hari Sabat itu.

Berdasarkan berbagai peristiwa konflik Sabat yang terjadi antara Yesus dengan orang Farisi, penulis mencatat bahwa tuduhan-tuduhan orang Farisi terhadap Yesus adalah berhubungan dengan faktor tindakan-tindakan yang dianggap sebagai pelanggaran akibat melakukan suatu pekerjaan, seperti kegiatan penyembuhan oleh Yesus atau memetik bulir gandum oleh para murid. Sebaliknya tidak ada tuduhan yang berkaitan dengan pelanggaran Sabat akibat kesalahan dalam beribadah, berdoa dan pembacaan kitab suci. Di sini penulis menggarisbawahi bahwa kegagalan orang Farisi dalam memahami kesalehan dalam merayakan Sabat adalah :

Pertama, orang Farisi telah gagal mengenali relasi antara Sabat dengan Yesus sebagai Sang Pemilik otoritas atas Sabat. Realita kegagalan ini terjadi karena tidak adanya pengetahuan akan Allah dengan benar, seperti yang dikatakan Calvin dalam tafsirannya dalam Yeremia 10:25, "...knowledge of God (cognitio Dei) as the beginning of pietas."33 Konsekuensinya orang Farisi tidak bisa mempercayai dan menerima bahwa pemilik Sabat yang

32 Calvin, Institutes, 1.1.2.

33 John Calvin, Commentaries on the Prophet Jeremiah and Lamentation Volume I, terj. John Owen (Grand Rapids: Baker, 1993), 64-68. 
sesungguhnya telah datang di hadapan mereka, sehingga Yesus harus menegaskan bahwa diriNya-lah yang menjadi Tuhan atas hari sabat. Memisahkan Sabat dengan Sang Pemilik Sabat adalah sesuatu yang ironis.

Kedua, sebagai konsekuensinya, orang Farisi juga gagal melihat relasi antara Sabat Anak Manusia dengan kesalehan yang benar. Orang Farisi telah mempersempit definisi kesalehan sebatas hanya ada di dalam rumah ibadat saja, dan kesalehan tidak ada di luar rumah ibadat. Dengan kata lain, tidak ada kesalehan dalam bentuk pekerjaan yang merupakan suatu keharusan dan berbelas kasihan yang boleh dilakukan pada Sabat. Dalam hal ini Westminster Confession of Faith XXI.8., menjelaskan bahwa jenis-jenis pekerjaan tertentu boleh dilakukan secara pribadi maupun publik pada Sabat. ${ }^{34}$ Tuhan Yesus pernah mengecam sikap orang Farisi yang tampak beragama di bagian luarnya saja dengan mengatakan bahwa mereka adalah “orang-orang munafik, yang sama seperti kuburan yang dilabur putih, yang sebelah luarnya memang bersih tampaknya, tetapi yang sebelah dalamnya penuh tulang belulang dan pelbagai jenis kotoran. “35

Ketiga, orang Farisi memahami kesalehan secara dikotomi, menekankan pada aspek jiwa dan mengabaikan tubuh. Calvin memberikan tafsirannya pada Yehezkiel 18:5, dengan menekankan bahwa kesalehan bukan hanya diwujudkan dengan menghormati Allah, tetapi juga menghubungkannya dengan unsur kasih. Hormat/ takut akan Allah juga diwujudkan dengan melakukan keadilan dan kebenaran terhadap sesama. Sabat Anak Manusia mengintegrasikan keduanya, baik pelayanan jiwa maupun tubuh, karena keduanya saling terkait dalam diri manusia.

34 Westminster Confesions of Faith, XXI.8. "This sabbath is then kept holy unto the Lord, when men, after a due preparing of their hearts, and ordering of their common affers before hand, do not only observe an holy rest all the day from their own works, words, and thoughts about their wordly employments and recreations; but also are taken up the whole time in the public and private exercises of his worship, and in the duties of necessity and mercy."

35 Lih. Mat. 23:27. 
Keempat, orang Farisi memegang prinsip yang salah tentang kesalehan dari kehidupan umat Allah, bahwa kesalehan dapat dicapai dengan pelayanan yang "baik" dalam ibadah. Untuk ini Calvin mengatakan ${ }^{36}$ kesalehan sejati dapat dipahami dengan memperhatikan kata yang saling terjalin, yaitu: "faith, fear, reverence, love, knowledge." Dan dalam Institutes, ${ }^{37}$ Calvin menegaskan pula bahwa kesalehan, dan kesucian hidup Kristen hanya dapat dicapai dengan berpusat pada Kristus. Kesalehan ini mencakup dua aspek: Pertama, di dalam hati dengan menyangkal diri dan kedua, mengikuti jejak Kristus yaitu dengan jalan memikul salib. Hal ini tentunya menjadi peringatan bagi setiap "pelayan Tuhan" di dalam segala bentuk pelayanan yang dilakukan di dalam gereja, apakah sudah memahami Sabat Anak Manusia dengan benar atau belum.

Pemahaman kesalehan orang farisi yang keliru dan picik ini mungkin saja berpengaruh pada orang Kristen ketika merayakan Sabat di hari Minggu tanpa rasa hormat dan kasih kepada Allah dan yang sesungguhnya dapat diwujudkan dengan kasih/belas kasihan kepada sesama, dan merupakan refleksi dari pengenalan akan Allah yang besar dan mengasihi manusia yang menjalankan Sabat. Ford Lewis Battles menjelaskan bahwa Calvin membuat relasi antara kesalehan dan kasih, orang Kristen mengasihi Allah saat hidup bijaksana dengan menunjukkan kebaikan terhadap sesama. ${ }^{38}$ Dengan demikian ketika seorang Kristen merayakan Sabat seperti yang Calvin maksudkan, maka orang itu bukan hanya pergi ke gereja untuk beribadah kepada Allah agar semakin mengenalNya dengan benar, namun juga sekaligus tidak melalaikan tanggung jawabnya untuk senantiasa mewujudkan kasih kepada orang lain, dengan melakukan keadilan dan kebenaran. Kasih sebagai bukti ibadahnya kepada Allah, yang memenuhi perintah Allah untuk menjalankan Sabat.

\footnotetext{
36 Ford Lewis Battles, ed., The Piety of John Calvin (Phillipsburg: P\&R, 2009), 27.

37 Calvin, Institutes, 3.6.10.

38 Battles, The Piety of Calvin, 28.
} 


\section{Relasi Sabat Yahudi dan Kristen dengan Persatuan Mistis ${ }^{39}$}

Sebelum membahas relasi Sabat Yahudi dan Sabat Kristen, sebaiknya memperhatikan uraian Calvin dan tradisi Reformed tentang tiga manfaat mengapa hukum Taurat ini diberikan kepada umat Allah. Pertama, untuk mengendalikan dan membimbing. Kedua, untuk meyakinkan akan adanya dosa. Ketiga, untuk mengarahkan kehidupan orang-orang percaya kepada kehidupan yang benar. ${ }^{40}$ Melalui tiga fungsi hukum Taurat itu, maka penulis memperoleh pemahaman yang lebih baik akan korelasi Sabat Yahudi dengan Sabat Kristen. Ketika Calvin menafsir kitab Keluaran 20:811,41 Calvin menjelaskan bahwa Sabat menjadi tanda yang membedakan antara Israel dengan bangsa lainnya. Perbedaan Sabat bangsa Israel yang dimaksud di sini adalah karena Allah menyucikan umatNya. Walaupun demikian Allah juga menuntut umatNya agar berperan aktif dalam kesucian yang Allah kerjakan itu, dengan cara berhenti dari segala pekerjaan mereka selama enam hari itu dan memberikan waktu satu hari kepada Allah, agar Allah dapat bekerja di dalam diri mereka. Douma juga mengatakan bahwa menafsir Dekalog harus secara rohani, karena kedalaman pemahaman dari Dekalog itu baru tampak bila kita melihat bahwa itu semua sudah digenapi di dalam Kristus dan bukan ketaatan lahiriah melainkan hati. ${ }^{42}$ Hukum Sabat dalam Dekalog yang Allah berikan melalui Musa, yang semestinya menjadi penuntun bagi kesucian kehidupan umat Allah kini berubah menjadi praktek-praktek kesalehan yang legalis. Dengan begitu banyaknya pelanggaran dan kejahatan Israel, yang salah satunya ditunjukkan dengan

\footnotetext{
39 Calvin, Institutes, 3.11.10. Menguraikan pengertian Persatuan Mistis sebagai: " Therefore, that joining together of Head and members, that indwelling of Christ in our hearts-in short, that mystical union are accorded by us the highest degree of importance, so that Christ, having been made ours, makes us sharers with him in the gifts with which he has been endowed. We do not, therefore, contemplate him outside ourselves from afar in order that his righteousness may be imputed to us but because we put on Christ and are engrafted into his body-in short, because he deigns to make us one with him."

$40 \quad$ Ibid., 2.8.5.

41 Calvin, Commentaries on the Four Last Books of Moses, 434.

42 Douma, The Ten Commandments, 12.
} 
pelanggaran Sabat, maka Allah membuang umatNya ke Babel. Israel sebagai umatNya telah menajiskan, menginjak-injak, dan melanggar kekudusan SabatNya seperti yang difirmankanNya kepada nabi Yesaya dan Yehezkiel. ${ }^{43}$ Dan akhirnya dalam pelayanan nabi Yeremia dan Yehezkiel bangsa Israel masuk ke dalam masa pembuangan di Babel. Stephen Tong mengatakan bahwa selama dalam pembuangan bangsa Israel merayakan Sabat Babilonia:

Sabat yang yang tertulis di dalam kitab Yeremia: Pada hari itu, engkau tidak akan mengatakan“aku pernah diperbudak di Mesir" melainkan "aku pernah ditawan ke Babilonia." Jadi kau memelihara hari Sabat karena kau pernah ditawan di Babilonia dan Tuhanlah yang membawamu kembali ke tanah perjanjian yang Dia janjikan pada nenek moyangmu. Penekanan di sini bukan lagi "hari," melainkan alasan mereka memelihara Sabat, yaitu campur tangan Tuhan dalam membebaskan mereka dari penawanan. ${ }^{44}$

Dalam masa pembuangan di Babel ini, orang Israel banyak dipengaruhi oleh bangsa Babel yang merayakan shappatu $u^{45}$ yang mirip Sabat, di mana mereka libur dari pekerjaan karena takut kena hukuman dari rohroh jahat, berbeda dengan Sabat Yahudi yang dirayakan bangsa Yahudi karena sebagai penghormatan kepada Allah. Di masa pembuangan inilah dampak dari pemikiran bangsa Asyur dan Babel mempengaruhi pemikiran perayaan Sabat Yahudi. Memelihara hari Sabat menjadi salah satu upaya yang harus dilakukan manusia supaya bisa selamat. Maka, para tua-tua dan para rabi sangat senang menjabarkannya secara mendetail apa yang boleh dan tidak boleh dilakukan pada hari Sabat, yang tertuang dalam Talmud.

43 Lih. Yes. 58:13; Yeh. 20:13; 22:8.

44 Stephen Tong, Sepuluh Hukum-Hukum Keempat, diakses 28 Oktober 2014, http://www.buletinpillar.org/transkrip/sepuluh-hukum-hukum-keempat.

45 J.I. Packer, Everyday Life in the Bible (New York: Random House, 1989),120. Bdk.The Interpreter's Dictionary of the Bible (New York: Abingdon Press, 1962), 135. It was designated specifically as "the day of quieting the heart "...furthermore, the seventh, fourteenth, twenty first, and twenty eight days of certain months, and not improbably of every month, and likewise the nineteenth dayi.e the forty ninth, the seven times seventh, day from the first day of the preceeding month-were regarded as "evil days." 
Tuhan Yesus mengecam dengan keras praktek Sabat Yahudi yang legaslis ini karena praktek Sabat ini telah mengacaukan maksud dan tujuan Sabat yang Allah telah berikan kepada umat pilihanNya itu. Calvin menjelaskan, Tuhan Yesus memberikan teladan untuk tetap memelihara Sabat yaitu dengan pergi ke Sinagoge, ${ }^{46}$ dengan cara membaca kitab suci, beribadah dan merenungkan firman. Demikian pula dengan Paulus yang "melanjutkan" Sabat Yahudi bagi orang Kristen, dengan cara berkumpul bersama untuk mendengarkan firman, berdoa bersama, dan melatih kerohanian. Calvin menyimpulkan bahwa untuk tujuan inilah Sabat Yahudi dilanjutkan dengan Sabat Kristen pada hari Minggu/ the Lord's day. "It was for this purpose that the Jewish Sabbath was succeeded by the Lord's Day." ${ }^{4}$ Pelaksanaan Sabat hendaknya mengikuti petunjuk, seperti yang diberikan dalam Perjanjian Baru tentang gereja yang berkumpul bersama demi suatu keteraturan seperti nasehat rasul Paulus kepada jemaat di Korintus.

Jikalau diperhatikan, Sabat yang Yesus ajarkan dan diteruskan oleh gereja mula-mula bukanlah perayaan Sabat yang penuh beban seperti Sabat Yahudi yang dipraktekkan oleh para rabi/ orang Farisi dan ahli Taurat pada waktu itu. Sabat Kristen yang Yesus ajarkan adalah Sabat yang penuh sukacita, ucapan syukur, dan melegakan, karena itu setiap orang percaya diberi kesempatan untuk meninggalkan Sabat Yahudi yang merupakan bayang-bayang dan memasuki Sabat Kristen yang sudah diredefinisi ulang oleh Kristus pemilik otoritas atas Sabat Kristen. Dengan demikianrelasi

46 Merrill C. Tenney, New Testament Survey, rev. ed. (Grand Rapids: Eerdmans, 1985), 93. Dijelaskan bahwa: Sinagoge mempunyai peranan besar dalam pertumbuhan dan kelestarianYudaisme. Sinagoge berfungsi sebagai balai sosial di mana penduduk Yahudi di kota yang bersangkutan berkumpul setiap Minggu untuk berjumpa satu dengan lainnya. Sinagoge juga menjadi sarana pendidikan untuk tetap memelihara hukum Taurat dan mendidik anak-anak mereka dalam iman/kepercayaan nenek moyangnya. Sinagoge menggantikan Bait Allah yang sulit dijangkau karena jarak yang jauh dan karena ketiadaan biaya.

47 John Calvin, Commentary on a Harmony of Evangelists, terj. William Pringle (Grand Rapids: Baker, 1993), 227. 
Sabat Kristen dengan persatuan mistis dapat dilihat dari beberapa faktor sebagai berikut:

Pertama, seorang Kristen harus memahami bahwa Sabat Kristen, yang ia rayakan setiap hari Minggu itu bisa terjadi karena pengorbanan dan penderitaan Kristus di kayu Salib. Melalui pengertian pertama ini, ia tidak akan memandang anugerah yang diterimanya itu sebagai anugerah murahan, seperti yang dipertegas oleh Dietrich Bonhoeffer sebagai "Cheap grace is grace without discipleship, grace without the cross, grace without Jesus Christ, living and incarnate." 48 Calvin menekankan bahwa persatuan dengan Kristus akan menghasilkan anugerah ganda/ twofold grace ${ }^{49}$, yaitu pembenaran dan penyucian, yang dapat dibedakan namun tak dapat dipisahkan. Dengan diperolehnya pembenaran dan penyucian maka seluruh manfaat keselamatan juga akan diperoleh oleh mereka yang dipersatukan dengan Kristus. Dengan pemahaman persatuan mistis yang pertama ini, tentunya akan memberikan pengharapan dan sukacita besar bagi setiap orang Kristen yang merayakan Sabat Kristen pada setiap hari Minggu, karena Kristuslah yang telah mempersatukan setiap umat pilihan dan membawanya kembali kepada Allah Bapa, yang sejak awal telah memerintahkan Sabat di dalam Perjanjian Lama.

Kedua, melalui persatuan mistis ini, maka setiap orang Kristen menerima pembenaran oleh karena anugerah yang merupakan imputasi kebenaran Kristus dan orang Kristen menerimanya hanya oleh karena iman saja. Pembenaran ini akan memimpin kemalasan rohani dan ketidakpedulian rohani kepada hidup yang suci. Imputasi kebenaran Kristus kepada orang Kristen menunjukkan bahwa ia bukan orang benar, melainkan diperhitungkan atau dianggap benar karena ia ada di dalam Kristus. Calvin mengatakan, "and in such a way that his divinity and our human

48 Dietrich Bonhoeffer, Witness to Jesus Christ, ed. John de Gruchy (Bungay: Collins, 1987), 158.

49 Calvin, Institutes, 3.3.1. 
nature might by mutual connection grow together." 50 Penekanan aspek pembenaran karena iman dipersatukan dalam Kristus begitu penting dalam merayakan Sabat Minggu. Pertama, setiap orang Kristen akan mengingatkan dirinya bahwa ia bukan orang benar melainkan dibenarkan di dalam Kristus. Kedua, setiap orang Kristen tidak akan memandang rendah orang lain karena merasa diri sendiri sudah benar, melainkan akan memiliki kerinduan agar orang lain juga dapat mengecap anugerah pembenaran seperti yang telah dialaminya. Ketiga, setiap orang Kristen akan menerima penyucian sebagai aspek yang tak terpisahkan dalam pembenaran yang diterimanya dalam persatuan dengan Kristus. Penyucian dan pembenaran ini diberikan kepada iman orang Kristen itu secara bersamaan, sehingga tidak menentukan prioritas urutan penyucian atau pembenaran, yang mana lebih dahulu. Di sinilah peran Roh Kudus sebagai pengikat yang mempersatukan antara Kristus dengan orang percaya.Tepat seperti yang Calvin katakan bahwa: "To sum up, the Holy Spirit is the bond by which Christ effectually unites us to himself." 51 Roh Kudus inilah yang akan terus menerus menyucikan orang percaya itu, baik di hari kerja, maupun di hari Sabat. Baik secara pasif, karena telah memperolehnya dari persatuannya dengan kristus dalam persatuan mistis, juga secara aktif dengan pertolongan Roh Kudus mengusahakan pertobatan yang terus menerus.

Ibid., 2.12.1.

Ibid., 3.1.1. 


\section{Relasi Konsep Sabat dengan Kesucian Kolektif (Jemaat/Gereja)}

Relasi Sabat sebagai Sakramen ${ }^{52}$ dengan Natur Gereja

Selain Sabat sebagai simbol dan bayang-bayang dari Sabat yang sudah digenapi dalam Kristus, Sabat juga adalah sebagai sakramen. Dalam hal ini memang Calvin memakai istilah yang sama dengan dua sakramen yang sudah disepakati oleh para reformator yaitu sakramen perjamuan kudus dan baptisan kudus. Penulis sependapat dengan Calvin bahwa Sabat sebagai sakramen ini dimaksudkan dalam pemahaman yang luas, agar semakin meyakinkan umat Allah bahwa Sabat adalah tanda dari suatu kebenaran akan janji Allah. ${ }^{53}$ Jadi jelasnya, Sabat adalah alat bukan tujuan. Allah memakai Sabat sebagai alat, membuat suatu regenerasi dalam umatNya, suatu kehidupan yang baru yang di dalamnya terdapat pembenaran, pertobatan dan penyucian seperti yang disampaikan oleh Louis Berkhof dalam Systematic Theology ${ }^{54}$ dan demikian pula Gordon J. Spykman dalam Reformational Theology. ${ }^{55}$ Sebelum masuk dalam pembahasan perihal tanda gereja (sakramen), penulis memandang perlu untuk memperhatikan natur gereja yang dalam implikasinya berkaitan dengan tugasnya menjalankan sakramen itu. Gereja secara naturnya bukanlah berbicara tentang bangunan gereja, melainkan komunitas sosialnya, yaitu orang-orang yang telah diperdamaikan dengan Allah. Craig

\footnotetext{
52 Lih. artikel Rendy Tirtanadi, "Perayaan Sabat Menurut John Calvin" dalam Jurnal Teologi Verbum Christi, Vol. 2, No. 1, A pril 2015 (Jakarta: STT Reformed Injili Internasional), 203-206.

53 Calvin, Institutes, 4.14.18.

54 Louis Berkhof, Systematic Theology (Grand Rapids: Eerdmans,1941), 531. Berkhof mengatakan bahwa secara tidak langsung gagasan tentang kesucian juga diaplikasikan kepada sesuatu dan manusia yang memiliki relasi khusus dengan Allah, sesuatu itu bisa jadi adalah tanah Kanaan, kota Yerusalem, bait Allah, gunung, hari Sabat dan hari-hari perayaan Israel lainnya, "they are called holy, since they are consecrated to God and are placed within the radiance of His majestic holiness."

55 Gordon J.Spykman, Reformational Theology, A new Paradigm for Doing Dogmatics (Grand Rapids: Eerdmanns, 1992), 487. Sakramen sebagai means of grace, membawa seorang Kristen kepada pembenaran, pertobatan dan penyucian.
} 
van Gelger mengatakan dalam "The Essence of the Church," empat gambar utama yang melukiskan tentang gereja sebagai komunitas sosial: Gereja adalah umat Allah, tubuh Kristus, komunitas orang kudus dan hasil karya dari Roh Kudus. ${ }^{56}$

Penulis berpendapat bahwa Sabat sebagai sakramen bukan hanya sebagai alat anugerah melainkan juga sebagai alat pengingat "remembrance" yang harus terus menerus dilakukan di sepanjang kehidupan umat Allah. Alkitab mencatat bahwa sejak bangsa Israel keluar dari perbudakan di Mesir, Allah melalui para nabi, yang dimulai dari Musa sampai kepada nabi Yehezkiel ${ }^{57}$ senantiasa memperingatkan umatNya untuk tetap mengingat perayaan Sabat. Melupakan SabatNya sama saja dengan melupakan Allah Sang Pemberi Sabat. Alkitab juga mencatat bagaimana umat Allah melupakan SabatNya dan akhirnya Allah menghukum dengan membuang umatNya ke Babel selama 70 tahun lamanya. ${ }^{58}$

Untuk itu, sebelum Yesus kembali ke surga, Ia memerintahkan untuk melaksanakan dua sakramen kepada para muridNya yaitu untuk melakukan baptisan kudus dan perjamuan kudus, agar gerejaNya senantiasa mengingat akan anugerah sekaligus juga perintahNya.

Pertama, sakramen baptisan kudus. Melalui baptisan kudus, pertama maka setiap orang percaya di dalam gerejaNya bisa menyatakan iman. Kedua, menyatakan pengakuan iman di hadapan jemaat dan ketiga, di dalam baptisan kudus setiap orang percaya bukan hanya dipersatukan dengan kematian dan kebangkitan Kristus, melainkan juga bisa menerima berkat-berkatNya. ${ }^{59}$ Selain itu Calvin juga melihat bahwa baptisan sebagai

\footnotetext{
56 Craig van Gelger, The Essence of the Church, (Grand Rapids: Baker, 2000), 108.

57 Yehezkiel diperkirakan melayani sebagai nabi pada tahun 593-570 SM, pada konteks penghancuran kerajaan Yehuda dan Yerusalem dan dalam masa pembuangan di Babilonia. Pada saat itu, Samaria sudah jatuh yaitu pada tahun 722/1 SM. Bdk.Yeh. 20:12 " Hari-hari SabatKu juga kuberikan kepada mereka menjadi peringatan di antara Aku dan mereka..." dan Yeh. 22:8."..hari-hari Sabat-Ku kau najiskan."

58 Yer. 25:11.

59 Calvin, Institutes, 4.15.1-6.
} 
tanda permulaan di mana orang percaya diterima ke dalam masyarakat gereja, agar dicangkokkan dalam Kristus, dan diperhitungkan di antara anak-anak Allah. ${ }^{60}$

Kedua, sakramen perjamuan kudus. Sakramen yang dilakukan gereja sebagai bentuk ketaatan akan perintah Yesus. Sebelum Kristus makan dan minum bersama para muridNya itu, Ia berkata: “Inilah tubuh-Ku, yang diserahkan bagi kamu; perbuatlah ini menjadi peringatan akan Aku! Cawan ini adalah perjanjian baru yang dimeteraikan oleh darah-Ku; perbuatlah ini, setiap kali kamu meminumnya, menjadi peringatan akan Aku!" 61 Pelanggaran terhadap sakramen perjamuan kudus yang terjadi di jemaat Korintus, telah mendapatkan teguran keras dari rasul Paulus waktu itu, sehingga hukuman berupa kelemahan tubuh sampai yang paling keras yaitu kematian "terpaksa" diberlakukan bagi pelanggar sakramen perjamuan kudus itu. ${ }^{62}$

Di sini tampak adanya pengaruh relasi yang signifikan dari pelanggaran Sabat sebagai sakramen dalam kitab Perjanjian Lama, dan pelanggaran perjamuan kudus sebagai sakramen dalam kitab Perjanjian Baru. Calvin sendiri menempatkan sakramen sebagai suatu bagian yang sentral dari suatu ibadah, dan menjadi tanda yang kelihatan yang menopang iman umatNya yang penuh kelemahan.

Dengan deskripsi di atas, penulis ingin menyampaikan enam poin penting tentang relasi Sabat adalah sakramen dalam Perjanjian Lama dengan natur gereja Tuhan yang diimplementasikan melalui sakramen baptisan dan perjamuan kudus sebagai sakramen dalam Perjanjian Baru sebagai berikut:

Pertama, Sabat dalam Perjanjian Lama sebagai sakramen telah berakhir sejak kedatangan Kristus sebagai penggenapannya. Hal ini berarti

\footnotetext{
$60 \quad$ Ibid., 4.15.1.

61 1Kor. 11:24-25.

62 1Kor. 11:29-31.
} 
Sabat sebagai sakramen harus dimaknai sebagai hari untuk menjalankan sakramen di dalam gereja, yang akan membawa jemaat kepada Kristus, melalui perjamuan kudus dan baptisan kudus. Allah yang telah membebaskan umatNya dari perbudakan di Mesir, memanggil mereka keluar supaya mereka bisa pergi beribadah di padang gurun. ${ }^{63}$ Demikian pula Kristus telah memanggil keluar "ekklesia" yaitu gerejaNya, supaya beribadah padaNya pada hari Tuhan/ "the Lord's day"/ hari Minggu menjadi bangsa yang terpilih, imamat yang rajani, bangsa yang kudus, dan umat kepunyaan Allah sendiri (1 Pet. 2:9). Israel telah mendapatkan seluruh janji yang Allah pernah sampaikan melalui Musa (Kel. 19:6), yaitu sebagai kerajaan imam dan bangsa yang kudus, dan janji itu diberikan kepada bangsa lain juga, yaitu mereka disebut sebagai anak-anak Abraham, yaitu mereka yang percaya kepada Kristus.

Kedua, sakramen sebagai tanda dan meterai dari suatu janji Allah yang terdapat dalam Firman Allah. Sebagai tanda dan meterai, Calvin menegaskan tiga unsur penting dalam menjalankan sakramen ini. ${ }^{64}$ Pertama, menjalankan sakramen harus disertai dengan memperkatakan firman, sehingga memiliki kekuatan untuk mengatasi berbagai kelemahan. Maka penting sekali penyampaian Firman Allah melalui khotbah sebelum sakramen dilakukan, baik sakramen baptisan kudus maupun perjamuan kudus. Kedua, sakramen harus dijalankan dengan iman, agar berkat Allah dicurahkan. Dan yang ketiga, Roh Allah saja yang mengefektifkan sakramen bagi umat Allah, bukan kuasa yang berasal dari sakramen itu.

Ketiga, pentingnya sakramen sebagai pengingat umat Allah/ orang Kristen. Allah yang memahami segala kelemahan manusia telah beranugerah dengan memberikan dua tanda yang akan meyakinkan

63 Kel. 10:3.

64 Calvin, Institutes, 4.15.4. "A sacrament consists of the word and the outward sign. For we ought to understand the word not as one whispered without meaning and without faith, a mere noise, like amagic incantation, which has the force to consecrate the element. Rather, it should, when preached, make us understand what the visible sign means." 
jemaatNya bila mereka sedang dalam kelemahan dan keraguan iman, mereka boleh dikuatkan dengan mengingat baptisan kudus yang telah mereka terima dengan iman untuk menjadi milik Tuhan dan mengingat persatuan mereka dengan Kristus, melalui roti dan air anggur perjamuan. Oleh karena itu, jemaat seharusnya mengikuti perjamuan kudus dengan teratur dan gereja wajib melaksanakannya sesuai petunjuk kitab suci sesering mungkin. Calvin mengusulkan perjamuan kudus setidaknya sekali dalam seminggu, mungkin karena hendak melawan praktek perjamuan kudus yang dilakukan oleh Roma Katolik yang sangat jarang yaitu sekali dalam setahun. ${ }^{65}$

Keempat, pelanggaran terhadap sakramen akan menerima hukuman yang serius. Hukuman mati yang diterima oleh mereka yang melanggar kekudusan Sabat, merupakan bentuk keseriusan Allah terhadap kudusnya Sabat, demikian halnya dengan penghinaan terhadap sakramen perjamuan kudus yang ditulis oleh rasul Paulus dalam 1 Kor. 11:30. Segala pelanggaran dan dosa jemaat Korintus yang melawan Allahmu telah mendapatkan hukuman berupa sakit penyakit dan bahkan kematian. Namun demikian semua itu bertujuan untuk mengoreksi jemaat Korintus sebagai natur gereja yang kudus.

Kelima, khusus mengenai perjamuan kudus kita harus memahami naturnya. Calvin menjelaskan lima natur perjamuan kudus, sebagai berikut:66 Perjamuan Tuhan merupakan karunia. Selanjutnya karunia itu

65 Ibid., 4.17.44-46. "What we have so far said of the Sacrament abundantly shows that it was not ordained to be received only once a yearand that, too, perfunctorily, as now is the usual custom. Rather, it was ordained to be frequently used among all Christians in order that they might frequently return in memory to Christ's Passion, by such remembrance to sustain and strengthen their faith, and urge themselves to sing thanksgiving to God and to proclaim his goodness; finally, by it to nourish mutual love, and among themselves give witness to this love, and discern its bond in the unity of Christ's body... It should have been done far differently: the Lord's Table should have been spread at least once a week for the assembly of Christians, and the promises declared in it should feed us spiritually."

66 David hall, ed., Tributes to John Calvin, A Celebration of His Quincentenary (Phillipsburg: P\&R, 2010), 398. 
adalah Yesus Kristus sendiri. Karunia itu diberikan dengan tanda-tanda. Karunia itu diberikan oleh Roh Kudus. Dan karunia itu diberikan kepada semua orang yang mengikuti perjamuan kudus.

Keenam, sakramen tetap berlanjut sejak zaman gereja mula-mula sampai saat ini, dan terus berlanjut dalam gerejaNya sampai kedatangan Kristus di akhir zaman untuk suatu penghakiman. Dengan demikian kehadiran Yesus dinyatakan dalam simbol melalui "visible form" dari roti dan air anggur, sehingga pikiran kita senantiasa diingatkan kepadaNya.

Dengan uraian di atas maka relasi Sabat sebagai sakramen dengan natur gereja dapat diaplikasikan kepada jemaat/ gereja yang adalah tubuh Kristus dan persekutuan orang kudus. Gereja sebagai persekutuan orang kudus, adalah merupakan kumpulan orang-orang yang telah memiliki pengalaman bersama Allah, sehingga setiap orang yang telah diperdamaikan oleh Kristus itu bisa saling berbagian satu terhadap yang lainnya. Allah melalui Roh Kudus-lah yang telah menciptakan persekutuan ini sehingga menjadi persekutuan orang kudus. Gereja sebagai persekutuan orang kudus inilah yang merayakan Sabat dan menjalankan sakramen di dalamnya.

\section{Relasi Sabat Eskatologis dengan Atribut Gereja}

Ada suatu perbedaan durasi waktu yang dapat dilihat antara Sabat Yahudi dengan Sabat Kristen. Sabat Yahudi bersifat temporer ${ }^{67}$ sedangkan Sabat Kristen bersifat kekal. 68 Kepemimpinan Yosua yang berhasil memimpin bangsa Israel memasuki tanah Kanaan sebagai tanah perjanjian menjadi Sabat simbolik bagi Sabat kekal yang ada dibawah kepemimpinan Yesus yang memimpin orang percaya ke tanah perjanjian yang kekal yaitu sorga. Sabat kekal inilah yang Calvin definisikan sebagai "Perpetual Sabbath

67 Calvin, Institutes, 2.8.29.

68 Ibid., 2.8 .30 . 
in which there is the highest felicity, when there will be a likeness between men and God to whom they will be united." 69 Demi mencapai Sabat kekal yang eskatologis ini, tidak ada cara lain kecuali dengan berhenti dari pekerjaan dunia, dan memberi diri bagi Allah bekerja di dalam umatNya. Walau harus dengan perjuangan yang tanpa henti dengan menyangkal diri dan mematikan kedagingannya. Dengan demikian Sabat eskatologis adalah Sabat yang mengandung pengharapan di mana terdapat eternal rest seperti yang dijanjikan dalam Ibrani 4:10. Jikalau Yosua telah berhasil memimpin bangsa Israel memasuki tempat perhentian yang final, tentunya tidak ada lagi janji Allah tentang suatu hari lain. Douma mengatakan adanya Sabat Yahudi maupun Sabat Kristen adalah tanda yang menunjuk kepada kebenaran, bahwa kita belum mencapai peristirahatan yang sesungguhnya seperti Allah yang berhenti dari pekerjaanNya. ${ }^{70}$

Penulis memandang bahwa Sabat eskatologis ini: Pertama, menjadi sebuah peringatan agar gereja memiliki iman terhadap injil kebenaran yang telah diberitakan dan yang berdiri atas ajaran para rasul. Iman inilah yang mempersatukan gereja dengan kebaikan Allah, melalui Roh Kudus gereja telah memasuki persekutuan dengan Kristus. Kedua, gereja harus memiliki ketaatan untuk melakukan firman yang dikhotbahkan pada setiap hari Sabat/ Minggu. Ketiga, gereja harus tetap berpengharapan bahwa Allah telah menyediakan peristirahatan terakhir dalam sabat eskatologis yang Allah telah tetapkan bagi gerejaNya.

Berkaitan dengan atribut gereja, penulis menarik beberapa relasinya dengan Sabat eskatologis sebagai berikut:

Pertama, gereja adalah "katolik." Keberadaan orang Kristen dalam suatu gereja tidak bersifat simbolik lagi, melainkan eksis dan sedang menuju Sabat eskatologis, oleh karena itu sebagai gereja yang memiliki sifat

69 Calvin, Commentaries Paul to Hebrews, 97-98.

70 Douma, The Ten Commandments, 141. 
universal, gereja harus tampil keluar dari zona nyamannya, dan berperan aktif dalam berbagai kegiatan pelayanan. Khususnya melalui pelayanan penginjilan sehingga gereja yang katolik sekaligus juga lokal, karena penginjilan di berbagai konteks budaya yang ada. Implementasi dari Sabat yang eskatologis, akan mengarahkan gereja agar giat melakukan amanat agung Kristus melalui penginjilan, karena Kristus akan datang kembali. Stephen Tong mengatakan "Mengapakah menginjili? Biarlah seluruh bumi mendengar kabar baik dari Tuhan!"71 Sabat eskatologis ini juga akan memberikan pemahaman gereja yang misioner, gereja tidak lagi membuat dikotomi antara misi dan gereja, karena keduanya sebenarnya saling terkait, dapat dibedakan namun tidak dapat dipisahkan. Allah Tritunggal adalah Allah yang misioner. ${ }^{72}$ Allah Bapa menciptakan dunia ini, Kristus menebus umatNya yang telah jatuh dalam dosa, dan Roh Kudus membentuk dan memimpin gereja sebagai umat Allah.

Kedua, gereja adalah suci karena merupakan ciptaan Allah, melalui pekerjaan Roh Kudus. Konsekuensinya simbol eksternal yang mempersatukan orang Yahudi berdasarkan garis keturunan kelahiran, digantikan dengan kelahiran baru oleh Roh Kudus yang melahirbarukan orang-orang percaya dalam gerejaNya sebagai community of the saints. Namun, sementara gereja yang suci itu masih berada dalam dunia yang penuh dosa, bagaimanakah gereja menjaga kesuciannya itu? Pertama, gereja harus mengingat entitas/ keberadaannya sebagai suatu yang bersifat rohani, karena berakar pada tujuan kekal dari Allah; dan sosial, karena memang memiliki organisasi. Kedua, gereja adalah suci secara naturnya, karena Roh Kudus hadir dan tinggal di dalam "gereja," dan gereja hadir melalui penebusan Kristus. Kesucian gereja, diterima karena karunia Allah dan sekaligus juga kesucian yang harus diperjuangkan karena harus

71 Stephen Tong, Life and Ministies in Pictures, 70 Years of Blessing, ed. Sutjipto Subeno, Solomon Yo, dan Andiati Trisnaningtyas (Surabaya: Penerbit Momentum, 2010), 15.

72 Gelger, The Essence of the Church, 30-31. 
menghidupi kesucian yang telah diterimanya itu dengan penuh ketaatan. Pengabaian terhadap atribut gereja yang suci, telah menjadikan gereja bersifat duniawi, di mana semua bentuk peribadatannya hanya bersifat external form religion saja. Memisahkan holy Sabbath dengan holy church akan memisahkannya pula dari Holy Spirit. Maksudnya, jika gereja dimaknai sebagai komunitas rohani, yang merupakan karya dari Roh Kudus, maka gereja itu akan terus menerus disucikan dan tidak akan pernah ditinggalkan. Namun sebaliknya jika gereja dimaknai sebatas sebagai komunitas sosial, yang terdiri dari orang-orang yang tidak dikuasai dan dipimpin oleh Roh Kudus, maka gereja akan kehilangan kesuciannya, dan berakhir pada gedung atau organisasi duniawi saja. Dalam hal kesucian inilah Calvin menyerukan pentingnya disiplin gereja. Namun sayangnya mayoritas orang memandang perihal disiplin gereja hanya sebagai suatu tindakan penghukuman dengan jalan mengekskomunikasi. Bagi Calvin tindakan ekskomunikasi secara esensi merupakan suatu tindakan yang positif ketimbang negatif, ekskomunikasi dipandang Calvin sebagai aspek pastoral gereja, dan merupakan aspek yang tak terpisahkan dari berlangsungnya pemberitaan Firman Allah dalam gereja. "Its goal ultimately was nothing other than promoting the honor of Christ and the holiness of the church. ${ }^{73}$ Oleh karena itu penulis sangat setuju dengan apa yang dilakukan Calvin bersama Farel ketika ia menjaga kesucian gereja yang dilayaninya di Geneva pada Januari 1537, yaitu dengan memberikan tiga hal yang penting bagi gereja: Buku penuntun organisasi gereja, buku pengakuan iman, dan sebuah buku katekisasi yang berisi pelajaran tentang agama Kristen. ${ }^{74}$

Ketiga, gereja yang apostolik. Bila gereja hendak menikmati keindahan dan kebahagiaan Sabat eskatologis sebagai spiritual rest yang sesungguhnya, maka kesucian gereja harus dibawah otoritas dan pengajaran

Hesselink, Calvin's First Catechism, 161.

Ibid. 
firman yang berasal dari para Rasul. Penerapan atribut gereja apostolik ini berkaitan dengan sejarah gereja abad pertengahan di mana otoritas gereja Roma Katolik pada waktu itu ada di tangan uskup, bahkan menurut Gelger juga berlaku bagi gereja Orthodox, Anglican Episcopal, dan Methodist. Persoalan otoritas ini diawali dengan sistem kepausan yang melegitimasi jabatannya itu sebagai kelanjutan dari otoritas kerasulan Petrus. ${ }^{75}$ Oleh sebab itulah Calvin meninggalkan gereja Roma Katolik, karena Calvin menilai bahwa gereja telah menolak Firman Allah, yang berarti telah menolak Kristus. ${ }^{76}$ Maka penekanan Calvin di sini adalah gereja yang benar eksis di mana Kristus ditinggikan sebagai kepala dari gereja. Hal ini dibuktikan dengan tanda Firman yang murni dikhotbahkan dan diperdengarkan dan sakramen dijalankan. Dengan memperhatikan pemaparan tentang sifat apostolik di atas, maka tidak bisa dipungkiri bahwa:

Pertama, tidak semua gereja akan merayakan Sabat eskatologis-nya, bisa jadi gereja hanya merayakan Sabat Minggu nya saja yang bersifat temporal bukan yang kekal. Kecuali di dalam segala kelemahan dan ketidaksempurnaannya itu gereja tetap mau dikoreksi dan memberikan kemuliaan hanya kepada Kristus sebagai kepala gereja, dan memberi diri untuk terus menerus disucikan sampai pada kekekalan. Rasul Paulus pun mengingatkan Timotius, bahwa gereja yang benar adalah dasar dari kebenaran Injil, gereja meneguhkan dan memelihara kebenaran yang dinyatakan oleh Kristus dan para rasulNya (1 Tim. 3:15).

Kedua, gereja yang benar dan yang palsu bukan dinilai dari besar kecilnya gedung/bangunannya, banyak sedikitnya jumlah jemaatnya, lama atau barunya gereja berdiri, melainkan dari kesetiaan gereja tersebut menghotbahkan kebenaran Firman pada setiap hari Sabat. Dengan demikian

75 Gelger, The Essence of the Church, 123.

76 Calvin, Institutes, 4.2.7-11 dan 4.2.3,4,6. 
jemaat dipersiapkan setiap Minggu untuk menikmati Sabat eskatologis, dalam "eternal rest" bersama Kristus Sang Firman Hidup dan Kepala Gereja.

\section{Kesimpulan}

Dengan memperhatikan analisa di atas, penulis menyimpulkan beberapa poin penting yang menjadi benang merah relasi konsep Sabat dengan kesucian hidup Kristen menurut Calvin sebagai berikut:

Pertama, salah satu tujuan Sabat sejak penciptaan sampai kepada kekekalan memang dimaksudkan agar umat Allah, baik secara personal maupun jemaat/ gereja bisa mengalami kesucian yang dikerjakan oleh Allah Tritunggal: Bapa, Anak dan Roh Kudus, dengan persatuan yang khusus dalam Kristus sebagai Mediator.

Kedua, tanpa Sabat yang benar, maka konsekuensinya tidak ada kesucian yang benar pula. Sabat yang benar adalah bukan sebatas merayakan Sabat sebagai tuntutan/ kewajiban agama Kristen saja, melainkan Sabat yang sesuai dengan tujuan Allah Tritunggal sebagai Sang Pemilik Sabat. Dengan demikian perayaan Sabat bisa lebih menekankan aspek yang substansial ketimbang sekedar formalitas belaka. Relasi antara Sabat dengan kesucian ini akan semakin tampak, saat memperhatikan kehidupan kerohanian umat Allah sendiri, baik umat Allah dalam konteks sejarah Israel, maupun orang Kristen dalam konteks sejarah gereja. Korelasi antara perayaan Sabat dengan kesucian secara individual maupun kolektif selalu memiliki korelasi yang signifikan.

Ketiga, perayaan Sabat bukan berfokus pada "hari"nya, melainkan pada "Sabat"nya, bukan pada makna harafiah berhenti rest dari berbagai kegiatan yang ada, namun harus memahami makna rohani dari kata rest yang ternyata begitu luas, khususnya rest dalam pengertian kembali kepada Allah yang maha Suci. Mengabaikan makna rohani dari sabat, akan membawa orang Kristen hanya menjalankan Sabat yang sebatas "external 
observance" yang berujung pada hukuman Allah karena telah menyimpang dari ketetapan Sabat yang sesungguhnya.

Keempat, relasi Sabat dengan kesucian, tidak dapat dipisahkan dengan pemahaman orang Kristen tentang doktrin eklesiologi yang benar. Hal ini menjadi tanggung jawab gereja di dalam memberikan edifikasi kepada jemaat sehingga mampu membedakan dengan benar tentang "the true and false church," agar gereja tempat jemaat mengikuti Sabat Minggu sungguh menjadi persekutuan orang kudus yang telah dipanggil keluar menjadi milik Allah Tritunggal.

Kelima, seperti halnya kita menantikan Sabat yang kekal bersamaNya, maka kesucian orang Kristen dan gereja harus bersifat misioner demi perluasan gerejaNya. Sabat/ ibadah Minggu harus mendorong jemaat bukan hanya beristirahat menikmati Allah, melainkan beristirahat untuk melakukan tugas pelayanan penginjilan keluar agar semakin banyak umat pilihan yang dapat menikmati Sabat eskatologis bersama Allah di dalam kekekalan. $^{77}$

77 Selaras dengan catatan kaki no. 43, secara positif, karya seni yang selaras dengan hukum Tuhan akan menjadi berkat bagi umat manusia melalui pembukaan nuansa-nuansa ciptaan yang terjadi ketika orang berjumpa dengan karya tersebut. Kita dapat mengingat bagaimana puisi-puisi di dalam Alkitab (Mazmur, Ratapan, Kidung Agung, dst) mencelikkan mata kita untuk dapat melihat lebih banyak alasan untuk mengucap syukur, memuji Tuhan, memuja Tuhan, dan berharap kepada-Nya di dalam kesesakan. Tetapi di sisi yang lain, ada juga kesenian-kesenian tertentu yang menutup mata batin kita dari kemuliaan Tuhan, mungkin dengan menerbitkan aneka keserakahan, ketakutan yang salah, dan hawa nafsu yang tidak patut, yang menyesaki pikiran dan hati kita sedemikian sehingga yang baik, yang indah, dan yang patut dipuji tidak dapat berdiam dalam kehidupan kita secara melimpah. 